\title{
Effect of vitamin D supplementation, directly or via breast milk for term infants, on serum 25 hydroxyvitamin D and related biochemistry, and propensity to infection: a randomised placebo-controlled trial
}

\author{
David D. Chandy ${ }^{1} \dagger$, Jahnavi Kare ${ }^{2} \dagger$, Shakal N. Singh ${ }^{2 *}$, Anjoo Agarwal ${ }^{3}$, Vinita Das ${ }^{3}$, Urmila Singh $^{3}$, \\ V. Ramesh ${ }^{4}$ and Vijayalakshmi Bhatia ${ }^{1 *}$ \\ ${ }^{1}$ Department of Endocrinology, Sanjay Gandhi Postgraduate Institute of Medical Sciences, Lucknow 226014, India \\ ${ }^{2}$ Department of Pediatrics, Queen Mary's Hospital, King George's Medical University, Lucknow 226003, India \\ ${ }^{3}$ Department of Obstetrics and Gynecology, Queen Mary's Hospital, King George's Medical University, Lucknow 226003, India \\ ${ }^{4}$ Department of Clinical Chemistry, Sanjay Gandhi Postgraduate Institute of Medical Sciences, Lucknow 226014, India
}

(Submitted 13 November 2015 - Final revision received 2 April 2016 - Accepted 4 April 2016)

\section{Abstract}

We assessed the effect of vitamin D supplementation on related biochemistry, infection and dentition of the infant. In a double-blind, placebo-controlled trial conducted in Lucknow, India (latitude $26^{\circ} \mathrm{N}$ ), 230 mother -newborn pairs were randomised to receive, for 9 months, $3000 \mu \mathrm{g} /$ month oral vitamin $\mathrm{D}_{3}$ by the mother (group A) or $10 \mu \mathrm{g} / \mathrm{d}$ by the infant (group B) or double placebo (group C). All babies received 15 min of sun exposure (unclothed) during massage. Infants' median 25-hydroxyvitamin D (25(OH)D) was lower in group C (median 45.3; interquartile range (IQR) $22-59.5 \mathrm{nmol} / \mathrm{l}$ ) than in groups A (median $60 \cdot 8$; IQR $41.3-80.5 \mathrm{nmol} / \mathrm{l}(P<0 \cdot 01)$ ) and B (median 61.3 ; IQR $41.3-75.3 \mathrm{nmol} / \mathrm{l}(P<0.05))$ at 3.5 months. Infant $25(\mathrm{OH}) \mathrm{D}$ correlated negatively with infant parathyroid hormone $(r-0.46, P<0 \cdot 01)$. Elevated alkaline phosphatase $(>7.5 \mu \mathrm{kat} / \mathrm{l})$ was significantly more frequent in group C babies (16\%) than in group A ( $4 \%$ ) or group B (0\%) babies. The number of days with respiratory or diarrhoeal infection by 9 months of age was higher in group C (median 46.5; IQR 14.8-73.3 d) than in group A (median 18.5; IQR 8.8-31.0 d $(P<0.01)$ ) or group B (median 13.0; IQR 7.0-28.5 $(P<0.05)$ ). We conclude that monthly maternal or daily infant supplementation with vitamin $\mathrm{D}$ along with sun exposure is superior to sun exposure alone in maintaining normal infant $25(\mathrm{OH}) \mathrm{D}$ at 3.5 months, and provide protection from elevated alkaline phosphatase and infectious morbidity.

Key words: Vitamin D: Lactation: Infants: Sunshine

Hypovitaminosis D is highly prevalent in India despite adequate sunshine. Factors responsible for this include inadequate exposure to sunshine, atmospheric pollution and skin pigmentation. Serious consequences of vitamin D deficiency include cardiac failure and hypocalcaemic seizures ${ }^{(1)}$. Transplacental transfer and breast milk concentration of vitamin D are low in mothers with poor vitamin D status during pregnancy and lactation ${ }^{(2-4)}$. Studies from India have shown $84-96 \%$ of mothers and infants at birth and at 3 months to have serum 25 -hydroxyvitamin D $(25(\mathrm{OH}) \mathrm{D})<20 \mathrm{ng} / \mathrm{ml}(50 \mathrm{nmol} / \mathrm{l})$, with winter mean $25(\mathrm{OH}) \mathrm{D}$ in women being as low as $5.9 \mathrm{ng} / \mathrm{ml}$ $(14.75 \mathrm{nmol} / \mathrm{l})^{(2,5)}$

High-dose $(160 \mu \mathrm{g}$ or $6400 \mathrm{IU} / \mathrm{d})$ vitamin $\mathrm{D}_{3}$ administered to the lactating mother was found to safely and significantly improve maternal $25(\mathrm{OH}) \mathrm{D}$ and mean milk antirachitic activity ${ }^{(6)}$. Ala-Houhala et $a l .{ }^{(7)}$ showed that a regimen of 50 (but not 25) $\mu \mathrm{g} / \mathrm{d}$ to the mother improved the nursing infant's serum $25(\mathrm{OH})$ $\mathrm{D}$ significantly. In the only study from India on postnatal supplementation of term infants, Kumar et $a l^{(8)}$ did not find any differences between the placebo and supplemented groups (receiving $35 \mu \mathrm{g}$ vitamin $\mathrm{D}_{3} /$ week) in mortality or hospital admissions (their primary outcomes) or referral to the outpatient clinic for moderate morbidity, although serum 25(OH)D was higher in the treated group. Current international recommendations mention $10 \mu \mathrm{g} / \mathrm{d}$ as routine supplementation for breastfeeding infants ${ }^{(3,4,9)}$.

However, no study from tropical countries has documented the result of specific sun exposure advice for infants. Furthermore, maternal supplementation must be explored as a means of supplementing the infant and mother at the same time. We undertook a study to document whether important biological correlates such as infant parathyroid hormone (PTH),

Abbreviations: 25(OH)D, 25-hydroxyvitamin D; IQR, interquartile range; PTH, parathyroid hormone.

* Corresponding author: V. Bhatia, fax +91 522266 8017, email vbhatia@sgpgi.ac.in; S. N. Singh, email drsn.singh@rediffmail.com

$\dagger$ These authors contributed equally to this work. 
hypocalcaemia, growth and propensity to infection would be favourably altered by vitamin D supplementation to the infant. We hypothesised that vitamin $\mathrm{D}_{3}$ supplementation to the lactating mother at a dose of $3000 \mu \mathrm{g} /$ month (which would be similar to a daily dose of $100 \mu \mathrm{g}$ ) would improve the vitamin $\mathrm{D}$ status in both lactating women and their breastfeeding infants and that this form of supplementation would be comparable to oral vitamin $\mathrm{D}_{3}$ supplementation of $10 \mu \mathrm{g} / \mathrm{d}$ to the infant and superior to placebo.

\section{Methods \\ Study design and subjects}

The study was carried out between September 2012 and June 2014 at the King George Medical University, and Sanjay Gandhi Postgraduate Institute of Medical Sciences, Lucknow (latitude $26^{\circ} \mathrm{N}$ ). In northern India, the monsoon season is concluding by mid September, December and January are the coldest months and intensely hot and dry weather is experienced from April through June. The study was conducted as per the guidelines laid down in the Helsinki Declaration, was approved by the institutional ethics committee of both hospitals and was registered in the clinical trials registry of the Indian Council for Medical Research (ctri.nic.in; CTRI/2012/09/002958). Parents provided written informed consent. All mothers giving birth in two maternity units of the institution, who intended to continue exclusive breast-feeding until the first 6 months and come to the hospital of birth for immunisation, were invited to participate. Exclusion criteria included (a) birth weight $\leq 2 \mathrm{~kg}$, (b) sick neonate admitted to the intensive care unit, (c) mother or infant on treatment with anticonvulsants or antitubercular drugs and (d) mothers who had received any vitamin D other than the $10 \mu \mathrm{g}$ present in Ca tablets. At the time period of this study, there exist no recommendations for vitamin D supplementation during pregnancy or lactation by the Indian government maternal health programme.

Intervention. After maternal blood sample was collected for serum 25(OH)D 2-4 d after delivery, mother-infant pairs were randomly assigned at birth to one of three treatment regimens described below, to be followed for 9 months. Numbers were computer-generated and allocation was done by one research staff who supervised medication distribution. This staff member was not involved in data collection.

Group A (indirect supplementation). Under supervision, mothers received oral vitamin $\mathrm{D}_{3} 3000 \mu \mathrm{g}$ (two sachets of $1500 \mu \mathrm{g}$ each) within $7 \mathrm{~d}$ of delivery, and then $3000 \mu \mathrm{g}$ at $1.5,2 \cdot 5$ and 3.5 months on routine immunisation visits also under supervision. At 3.5 and 6 months, mothers were provided oral vitamin $\mathrm{D}_{3}$ for the next 3 months and were instructed to take $3000 \mu \mathrm{g}$ monthly. The baby was given placebo syrup.

Group B (direct supplementation). The baby received $10 \mu \mathrm{g}$ vitamin D preparation orally daily until 9 months. The mother was given placebo sachets.
Group $C$ (control). Neither the baby nor the mother was given any vitamin $\mathrm{D}$ supplementation. Both were given their respective placebo.

Mothers were advised to get sun exposure for at least half an hour daily. All mothers were given $500 \mathrm{mg}$ of elemental Ca daily in the form of calcium carbonate, in two divided doses, in addition to instruction about dietary sources of $\mathrm{Ca}$. They were instructed to give their infants 15 min of traditional baby massage once a day, under the sun between 09.00 and 16.00 hours A printed pictorial leaflet was provided to all mothers explaining the benefits of sun exposure.

Data collection. Clinic visits were planned for baby age $1 \cdot 5,2 \cdot 5$, $3.5,6$ and 9 months. If visits were missed, then phone calls were made to remind the mother regarding the visit. After this reminder, a research staff visited the home and administered/ provided medication. At every clinic or home visit, the infant's anthropometry, health status and adherence to medicines were documented by tablet counting and visual inspection of the syrup bottles, and the importance of sun exposure was reiterated. With regard to vitamin D or placebo sachet after the 3.5-month visit, phone calls were made on the due date, reminding the mother to take her dose. Length was measured by an infantometer (NeoCare), weight by a digital weighing machine (Salter) and head circumference by a non-stretchable nylon tape.

Demographic information including education and income were reported by the parents. Socio-economic scoring was done as per the Kuppuswamy scale ${ }^{(10)}$, with income score updated as of September $2012^{(11)}$. Parents and researchers were blinded to treatment. Adherence evaluation included recording the number of missed doses of vitamin D drops and Ca tablets at each visit. Exposure to sunlight was stressed at every visit and by monthly phone calls. The type of feeding and the number of days the baby suffered respiratory or diarrhoeal illness was documented during monthly phone calls and at each visit. Diarrhoeal illness was reported telephonically by the mother and was defined as frequent stools with abnormal consistency, lasting $2 \mathrm{~d}$ or more. Respiratory illness was defined as the presence of rhinorrhoea, blocked nose, cough, sneeze or tachypnoea, with or without fever.

\section{Outcome measures}

The primary outcome was the infant's serum 25(OH)D at 3.5 months. Secondary outcomes were (a) serum Ca, P, alkaline phosphatase and plasma PTH, in infants at 3.5 months of age; (b) anthropometry including weight, length, head circumference and maximum diameter of the anterior fontanelle measured at 3.5, 6 and 9 months; (c) number of days the baby suffered diarrhoeal or respiratory morbidity within 9 months of life; (d) mother's serum $25(\mathrm{OH}) \mathrm{D}$ and calciuria at 3.5 months; and (e) number of teeth at 9 months across the three groups. All analyses were done as per protocol.

\section{Assays}

Plasma and serum samples from the mother and child were stored frozen at $-80^{\circ} \mathrm{C}$ for analysis of PTH and $25(\mathrm{OH}) \mathrm{D}$ by 
immunoradiometric assay and RIA, respectively (DiaSorin). Inter-assay and intra-assay $\mathrm{CV}$ for PTH are 9.7 and $12.2 \%$, respectively, and for $25(\mathrm{OH}) \mathrm{D}$ they are $8.2-11.0 \%$ and 8.6-12.5\%, respectively. Serum total $\mathrm{Ca}, \mathrm{P}$, alkaline phosphatase, albumin (both mother and infant) and urinary $\mathrm{Ca}$ and creatinine (mother) were measured (Randox) within $24 \mathrm{~h}$ of collection.

\section{Sample size}

The sample size of forty-nine in each group was calculated to detect a difference (effect size of $50 \%$ ) in mean $25(\mathrm{OH}) \mathrm{D}$ between groups, which gave the study $80 \%$ power at the 0.05 significance level. Assuming 33\% dropout, seventy-five participants per group or 230 mother-infant pairs in all were recruited.

\section{Statistical analysis}

Differences among groups for continuous variables were re-tested using ANOVA for normally distributed data or Kruskal-Wallis test for non-parametric data. Post hoc comparisons were done using the Bonferroni test. Group differences for categorical variables were analysed using $\chi^{2}$ or with Fisher's exact test. Pearson's test for normally distributed data and Spearman's test for non-parametric data were performed for correlations. Statistical significance was set at $P \leq 0.05$ with two-tailed testing. Data were analysed using SPSS version 21.0 statistical software for Windows.

\section{Results}

Of 2563 women who delivered during the 9-month period between September 2012 and June 2013 in two units of the department, 1819 did not meet inclusion and exclusion criteria (primarily as they resided far away and intended to follow up for immunisation visits closer to their home) and 514 declined consent (Fig. 1). Of 230 recruited mother-infant pairs, 152 came for the 3.5 month visit ( $66 \%$ response rate). Those who came for follow-up did not differ from those who were absent, in maternal (socio-economic score, and BMI and 25(OH)D 2-4 d after delivery) and infant (birth length, weight, head circumference, chest circumference and maximum anterior fontanelle diameter) characteristics (online Supplementary Table S1). Among those who came for follow-up, maternal and infant baseline characteristics did not differ among the groups (Table 1). There was no difference in the proportion of infants receiving formula in addition to breast milk, among the three groups, at 3.5 months $(31.6,27.4$ and $27.3 \%$ of groups $\mathrm{A}, \mathrm{B}$ and $\mathrm{C}$ babies, respectively, $P=\mathrm{NS}$ ). At 9 months, $90 \%$ of infants in group A, $88 \%$ in group B and $91 \%$ in group $C$ were still receiving breast milk $(P=\mathrm{NS}$ ). Missed $\mathrm{Ca}$ doses by mother and vitamin $\mathrm{D}$ doses of the baby were documented to be

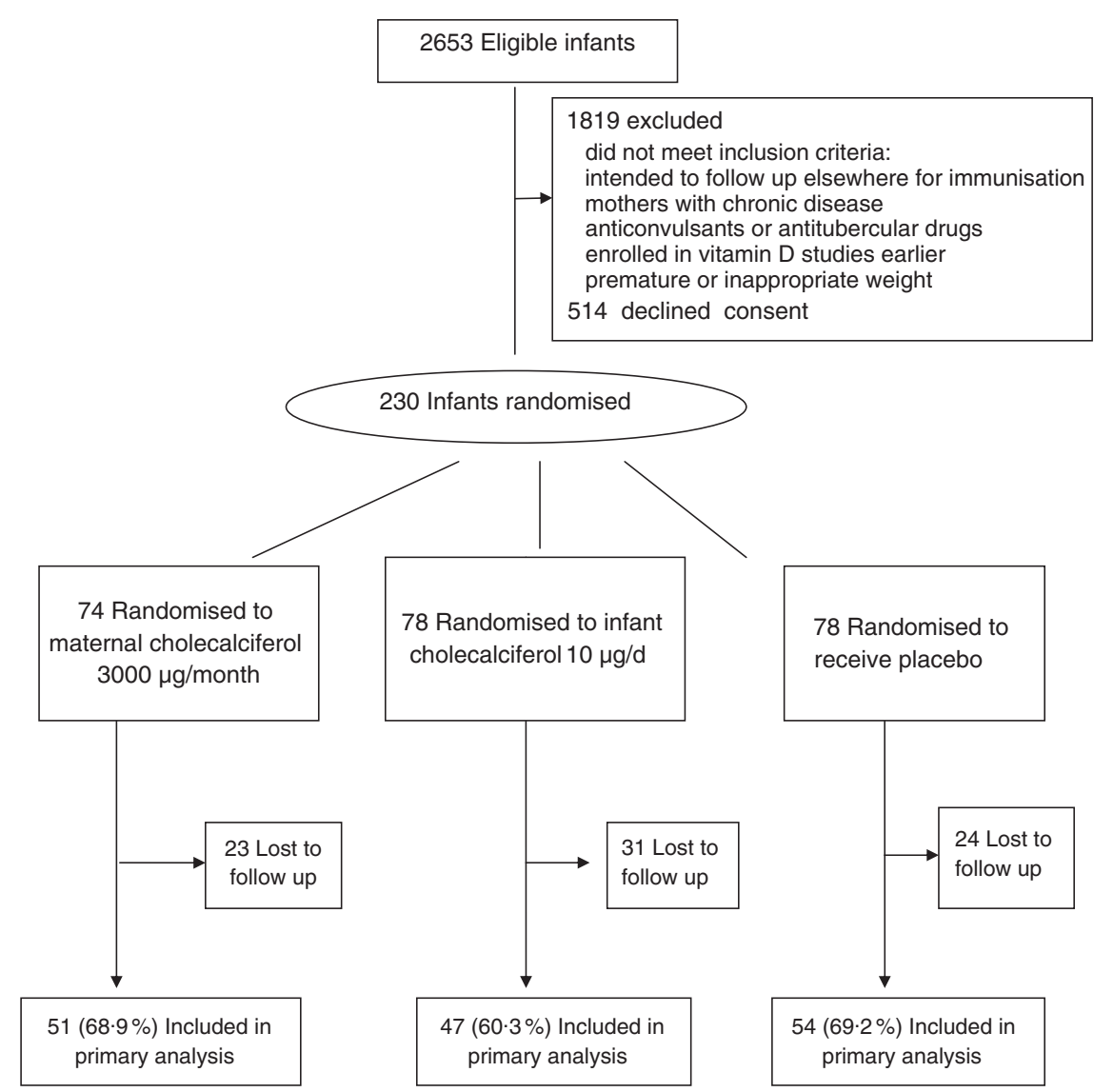

Fig. 1. CONSORT (CONsolidated Standards of Reporting Trials) diagram. Flow of participants in the study from screening to randomisation. 
Table 1. Baseline characteristics of mothers and infants

(Medians and interquartile ranges (IQR); mean values and standard deviations)

\begin{tabular}{|c|c|c|c|c|c|c|c|}
\hline \multirow[b]{2}{*}{ Variables (at delivery) } & \multicolumn{2}{|c|}{ Group A $(n 51)^{*}$} & \multicolumn{2}{|c|}{ Group B (n 47)† } & \multicolumn{2}{|c|}{ Group C $(n 54) \ddagger$} & \multirow[b]{2}{*}{$P$} \\
\hline & Median & IQR & Median & IQR & Median & IQR & \\
\hline \multicolumn{8}{|l|}{ Maternal baseline characteristics } \\
\hline Kuppuswamy socio-economic class score & 13.5 & $11-15$ & 13 & $12-15$ & 13 & $11-15$ & 0.78 \\
\hline BMI $\left(\mathrm{kg} / \mathrm{m}^{2}\right) \S$ & $22 \cdot 2$ & $20 \cdot 1-24.8$ & $22 \cdot 0$ & $19 \cdot 4-24 \cdot 1$ & 23.4 & $20 \cdot 8-25 \cdot 4$ & 0.53 \\
\hline 25(OH)D (nmol/l)\| & $22 \cdot 0$ & $13.5-31.3$ & $17 \cdot 8$ & $10 \cdot 3-28 \cdot 3$ & $20 \cdot 0$ & $13 \cdot 1-30 \cdot 3$ & 0.46 \\
\hline \multicolumn{8}{|l|}{ Infant baseline characteristics } \\
\hline Weight (kg) & $2 \cdot 75$ & $2 \cdot 50-3.00$ & $2 \cdot 68$ & $2.50-3.05$ & $2 \cdot 80$ & $2 \cdot 50-3 \cdot 20$ & 0.56 \\
\hline Length $(\mathrm{cm})$ & 47.5 & $45 \cdot 3-48 \cdot 7$ & 47.9 & $46 \cdot 5-49 \cdot 1$ & $47 \cdot 6$ & $46-49 \cdot 1$ & 0.40 \\
\hline Head circumference $(\mathrm{cm})$ & & & & & & & 0.41 \\
\hline Mean & \multirow{2}{*}{\multicolumn{2}{|c|}{$\begin{array}{r}33.00 \\
1.23\end{array}$}} & \multicolumn{2}{|c|}{$33 \cdot 20$} & \multicolumn{2}{|c|}{33.33} & \\
\hline SD & & & \multicolumn{2}{|c|}{1.50} & \multicolumn{2}{|c|}{$1 \cdot 12$} & \\
\hline Chest circumference $(\mathrm{cm})$ & $30 \cdot 0$ & $29 \cdot 0-31 \cdot 9$ & $30 \cdot 3$ & $29-31 \cdot 2$ & $30 \cdot 4$ & $29 \cdot 5-31.5$ & 0.75 \\
\hline Anterior fontanelle maximum diameter $(\mathrm{cm})$ & 3.0 & $2 \cdot 2-4 \cdot 0$ & 3.5 & $2 \cdot 8-4 \cdot 4$ & 3.0 & $2.4-4.5$ & 0.17 \\
\hline
\end{tabular}

25(OH)D, 25 hydroxycholecalciferol.

* Group A: mothers received oral vitamin $D_{3} 3000 \mu \mathrm{g}$ within $7 \mathrm{~d}$ of delivery, and then $3000 \mu \mathrm{g}$ at 1.5, 2.5, 3.5 months, under supervision. At 3.5 and 6 months, mothers were provided oral vitamin $D_{3}$ for the next 3 months and were instructed to take $3000 \mu \mathrm{g}$ monthly. The baby was given placebo syrup.

$\dagger$ Group B: the baby received $10 \mu \mathrm{g}$ vitamin D preparation orally daily. The mother was given placebo sachets.

$\ddagger$ Group C (control): neither the baby nor the mother was given any vitamin D supplementation. Both were given their respective placebo.

$\S$ BMI: both measurements $2-4 \mathrm{~d}$ after delivery.

|| To convert $25(\mathrm{OH}) \mathrm{D}$ from $\mathrm{nmol} / \mathrm{l}$ to $\mathrm{ng} / \mathrm{ml}$, divide by 2.5 .

$42 \cdot 2(\mathrm{sD} 32 \cdot 9)$ and $10 \cdot 1(\mathrm{sD} 10 \cdot 3)$ in group A, $36 \cdot 6(\mathrm{sD} 39 \cdot 1)$ and $16 \cdot 3$ (sD 11.9) in group B and $37 \cdot 3$ (sD $37 \cdot 8)$ and $15 \cdot 6(\mathrm{sD} 13 \cdot 1)$ in group $\mathrm{C}(P=0.59$ and $0 \cdot 19$, respectively).

The median $25(\mathrm{OH}) \mathrm{D}$ of infants at 3.5 months was significantly higher in groups A and B than in group C (Table 2). A similar result was obtained on analysing only those babies ( $n$ 109) who were not on fortified formula by 3.5 months. The fact that this difference is biologically relevant is suggested by the documentation of significantly higher median phosphate and lower proportion of babies with elevated alkaline phosphatase in group $\mathrm{B}$ than in group $\mathrm{C}$ infants, and significantly lower PTH in groups A and B infants than in group C infants. Infant total $\mathrm{Ca}$ levels did not differ among the groups, neither did the proportion of infants with hypocalcaemia. There was a moderately significant negative correlation of infant $\mathrm{Ca}$ with infant PTH (Spearman's $\rho-0.215, P<0.05$ ) and a positive correlation with mother 25(OH)D (Spearman's $\rho$ 0.337, $P<0 \cdot 01)$.

At 3.5 months, infants' $25(\mathrm{OH}) \mathrm{D}$ negatively correlated with their alkaline phosphatase (Pearson's $r-0.32, P<0.01$ ), PTH (Spearman's $\rho-0.46, P<0.01$ ) and mothers' PTH (Spearman's $\rho$ $-0.37, P<0.01)$ and correlated positively with mothers' $25(\mathrm{OH}) \mathrm{D}$ (Spearman's $\rho$ 0.444, $P<0 \cdot 01)$. Mothers' 25(OH)D levels correlated negatively with the infant PTH (Spearman's $\rho-0.337$, $P<0.01$ ) and mother's PTH (Spearman's $\rho-0.482, P<0.01$ ).

Growth patterns of the infants were similar between the groups throughout the study period (Table 3). Dental growth, as evidenced by the number of teeth, was in an age-appropriate way over time, with no differences by group. The morbidity over 9 months in terms of median days in diarrhoeal and respiratory illnesses was significantly higher in group C (median 46.5; interquartile range (IQR) $14.8-73.3 \mathrm{~d}$ ) than in group A (median 18.5; IQR $8.8-31.0 \mathrm{~d}, P<0.01$ ) or group B (median $13.0 ; 7-28.5 \mathrm{~d}$, $P<0.05)$. When differences between groups were looked for separately for diarrhoeal or respiratory illness, there was no statistically significant difference. Admission to hospital was needed by thirty-seven infants: fifteen in group $\mathrm{A}$ and eleven each in groups $\mathrm{B}$ and $\mathrm{C}$. The highest infant $25(\mathrm{OH}) \mathrm{D}$ was $134.8 \mathrm{nmol} / \mathrm{l}$ $(53.9 \mathrm{ng} / \mathrm{ml})$ and maternal $25(\mathrm{OH}) \mathrm{D}$ was $127 \cdot 8 \mathrm{nmol} / \mathrm{l}(51 \cdot 1 \mathrm{ng} / \mathrm{ml})$, with only one infant and two mothers (all from group A) having levels above $125 \mathrm{nmol} / 1(50 \mathrm{ng} / \mathrm{ml})$, which as per Institute of Medicine (IOM) may lead to potential adverse effects ${ }^{(9)}$. Several infants in all three groups showed transient hypercalcaemia. Maternal urinary Ca:creatinine ratios remained in the normal range for all groups (group A median 0.047 (IQR 0.024-0.142) mg/mg, group B 0.043 (IQR 0.028-0.102) mg/mg and group C 0.056 (IQR $0.042-0.083 \mathrm{mg} / \mathrm{mg}, P=\mathrm{NS}$ ). Hypercalciuria (urinary Ca:creatinine ratio $>0.2 \mathrm{mg} / \mathrm{mg}$ ) was seen in one mother each in groups $\mathrm{A}$ and $\mathrm{B}$. Hypercalcaemia (serum Ca $>10.5 \mathrm{mg} / \mathrm{dl} ; 2.62 \mathrm{mmol} / \mathrm{l}$ ) was not seen in any mother. There were no serious adverse events related to vitamin D supplementation.

\section{Discussion}

Our findings show that one oral dose of $3000 \mu \mathrm{g} / \mathrm{month}$ given to lactating women every month after delivery can provide adequate coverage for the breast-feeding infant up to 3.5 months. In addition, maternal supplementation greatly improved maternal vitamin D levels, thus providing for simultaneous improvement in maternal health. Provision of vitamin D directly or via breast milk was found to be superior to sunshine alone, as evidenced by improved biologically relevant parameters such as infant $P$ and alkaline phosphatase, as well as the number of days of respiratory or diarrhoeal infection in infancy. We did not have a second control group of mothers who were not given specific sun exposure advice. Our babies in group $\mathrm{C}$ had higher serum 25(OH)D (mean 43.75 (sD 26) nmol/1 $(17.5(\mathrm{sD} 10.4) \mathrm{ng} / \mathrm{ml})$ and median $45.25 \mathrm{nmol} / \mathrm{l}(18.1 \mathrm{ng} / \mathrm{ml}))$ than that reported by us in cord blood previously (mean serum 
Table 2. Biochemical parameters at 3.5 months' follow-up*

(Medians and interquartile ranges (IQR); mean values and standard deviations; numbers and percentages)

\begin{tabular}{|c|c|c|c|c|c|c|c|}
\hline \multirow[b]{2}{*}{ Variables } & \multicolumn{2}{|c|}{ Group A $(n 51) \dagger$} & \multicolumn{2}{|c|}{ Group B $(n 47) \ddagger$} & \multicolumn{2}{|c|}{ Group C $(n 54) \S$} & \multirow[b]{2}{*}{$P$} \\
\hline & Median & IQR & Median & IQR & Median & IQR & \\
\hline Mother 25(OH)D $(\mathrm{nmol} / \mathrm{l})$ & $65 \cdot 3$ & $49 \cdot 5-81 \cdot 8$ & $28 \cdot 3^{a}$ & $16 \cdot 5-36 \cdot 0$ & $26 \cdot 5^{\mathrm{a}}$ & $16 \cdot 8-38 \cdot 5$ & $\begin{array}{l}<0.01 \\
<0.05\end{array}$ \\
\hline $\begin{array}{l}\text { Mean } \\
\text { SD }\end{array}$ & \multicolumn{2}{|c|}{$\begin{array}{l}4.50^{\mathrm{b}} \\
2 \cdot 78\end{array}$} & \multicolumn{2}{|c|}{$\begin{array}{l}6 \cdot 86 \\
5 \cdot 17\end{array}$} & \multicolumn{2}{|c|}{$\begin{array}{l}8.06 \\
8.22\end{array}$} & $<0.05$ \\
\hline Baby 25(OH)D (nmol/l) & $60 \cdot 8^{\mathrm{c}}$ & $41 \cdot 3-80.5$ & $61 \cdot 3^{\mathrm{c}}$ & $41 \cdot 3-75 \cdot 3$ & $45 \cdot 3$ & $22 \cdot 0-59.5$ & $<0.01$ \\
\hline Baby 25(OH)D (>50 nmol/l) & & & & & & & 0.07 \\
\hline$n$ & \multicolumn{2}{|c|}{$31 / 51$} & \multicolumn{2}{|c|}{$28 / 47$} & \multicolumn{2}{|c|}{$22 / 54$} & \\
\hline$\%$ & \multicolumn{2}{|c|}{60.7} & \multicolumn{2}{|c|}{59.5} & \multicolumn{2}{|c|}{40.7} & \\
\hline Baby 25(OH)D (<25 nmol/l) & \multirow{3}{*}{\multicolumn{2}{|c|}{$\begin{array}{r}6 / 51 \\
11.7\end{array}$}} & & & & & 0.06 \\
\hline$n$ & & & \multirow{2}{*}{\multicolumn{2}{|c|}{$\begin{array}{l}5 / 47 \\
10 \cdot 6\end{array}$}} & \multicolumn{2}{|c|}{$14 / 54$} & \\
\hline$\%$ & & 11.7 & & & \multicolumn{2}{|c|}{25.9} & \\
\hline $25(\mathrm{OH}) \mathrm{D}$ of babies not on formula $(\mathrm{nmol} / \mathrm{l}) \|$ & $67 \cdot 2^{\mathrm{c}}$ & $45 \cdot 0-76 \cdot 5$ & $61 \cdot 3^{\mathrm{b}}$ & $41 \cdot 3-75 \cdot 2$ & $40 \cdot 2$ & $17 \cdot 0-58 \cdot 2$ & 0.001 \\
\hline Baby PTH $(\mathrm{pmol} / \mathrm{l})$ & $2 \cdot 31^{\mathrm{b}}$ & $1 \cdot 75-3 \cdot 20$ & $2 \cdot 29^{c}$ & $1.85-3.17$ & 3.06 & $2 \cdot 18-5 \cdot 26$ & $<0.01$ \\
\hline Baby Ca $(\mathrm{mmol} / \mathrm{l})$ & 2.52 & $2 \cdot 40-2 \cdot 57$ & $2 \cdot 47$ & $2 \cdot 32-2 \cdot 52$ & $2 \cdot 40$ & $2 \cdot 30-2 \cdot 54$ & 0.71 \\
\hline Baby $P(\mathrm{mmol} / \mathrm{l})$ & $2 \cdot 1$ & $1.6-2.5$ & $2 \cdot 2^{\mathrm{c}}$ & $1.9-2 \cdot 3$ & 1.9 & $1 \cdot 7-2 \cdot 1$ & $<0.01$ \\
\hline Baby Ca (>2.62 mmol/l) & & & & & & & 0.76 \\
\hline$n$ & \multicolumn{2}{|c|}{$7 / 50$} & \multicolumn{2}{|c|}{$8 / 47$} & \multicolumn{2}{|c|}{$6 / 51$} & \\
\hline$\%$ & \multicolumn{2}{|c|}{14.0} & \multicolumn{2}{|c|}{$17 \cdot 0$} & \multicolumn{2}{|c|}{$11 \cdot 7$} & \\
\hline Baby elevated ALP (>450 $7.5 \mu \mathrm{kat} /$ ) & \multicolumn{2}{|c|}{$2 / 50^{b}$} & \multicolumn{2}{|c|}{$0 / 46^{c}$} & \multicolumn{2}{|c|}{$8 / 50$} & $<0.01$ \\
\hline
\end{tabular}

25(OH)D, 25 hydroxycholecalciferol; PTH, parathyroid hormone; ALP, alkaline phosphatase, S, serum.

a $P<0.01$ v. group $A,{ }^{b} P<0.05 \mathrm{v}$. group $\mathrm{C},{ }^{\mathrm{c}} P<0.01 \mathrm{v}$. group $\mathrm{C}$.

* To convert 25(OH)D from $\mathrm{nmol} / \mathrm{l}$ to $\mathrm{ng} / \mathrm{ml}$, divide by 2.5 ; S. Ca from mmol/l to $\mathrm{mg} / \mathrm{dl}$, multiply by $4 ; \mathrm{S}$. P from mmol/l to $\mathrm{mg} / \mathrm{dl}$, $\mathrm{multiply} \mathrm{by} 3.09$; PTH from $\mathrm{pmol} / \mathrm{l}$ to $\mathrm{pg} / \mathrm{ml}$, $\mathrm{multiply} \mathrm{by} 9.4$.

† Group A: mothers received oral vitamin $D_{3} 3000 \mu \mathrm{g}$ within $7 \mathrm{~d}$ of delivery, and then $3000 \mu \mathrm{g}$ at $1.5,2.5,3.5$ months, under supervision. At 3.5 and 6 months, mothers were provided oral vitamin $D_{3}$ for the next 3 months and were instructed to take $3000 \mu \mathrm{g}$ monthly. The baby was given placebo syrup.

¥ Group B: the baby received $10 \mu \mathrm{g}$ vitamin D preparation orally daily. The mother was given placebo sachets.

$\S$ Group $C$ (control): neither the baby nor the mother was given any vitamin D supplementation. Both were given their respective placebo.

$\| n$ 109; thirty-five each in groups $\mathrm{A}$ and $\mathrm{B}$ and thirty-nine in group $\mathrm{C}$.

Table 3. Infants' anthropometry at 3.5 months

(Medians and interquartile ranges (IQR))

\begin{tabular}{|c|c|c|c|c|c|c|c|}
\hline \multirow[b]{2}{*}{ Variables } & \multicolumn{2}{|c|}{ Group A $(n 54)^{\star}$} & \multicolumn{2}{|c|}{ Group B $(n 52) \dagger$} & \multicolumn{2}{|c|}{ Group C ( $n 53) \ddagger$} & \multirow[b]{2}{*}{$P$} \\
\hline & Median & IQR & Median & IQR & Median & IQR & \\
\hline Weight (kg) & 5.8 & $5 \cdot 4-6 \cdot 1$ & $6 \cdot 0$ & $5 \cdot 4-6 \cdot 4$ & $5 \cdot 8$ & $5 \cdot 1-6 \cdot 4$ & 0.56 \\
\hline Length $(\mathrm{cm})$ & $61 \cdot 6$ & $59 \cdot 0-63 \cdot 0$ & $61 \cdot 6$ & $60 \cdot 5-63 \cdot 7$ & $60 \cdot 3$ & $58 \cdot 6-63 \cdot 1$ & 0.12 \\
\hline Head circumference $(\mathrm{cm})$ & 39.5 & $38.5-40.9$ & $40 \cdot 0$ & $38 \cdot 9-41 \cdot 1$ & $40 \cdot 0$ & $39 \cdot 0-41 \cdot 0$ & 0.42 \\
\hline Chest circumference $(\mathrm{cm})$ & 39.2 & $38.2-40.5$ & $38 \cdot 8$ & $37.9-40.9$ & 39.0 & $37.5-40.5$ & 0.74 \\
\hline Anterior fontanelle max. diameter $(\mathrm{cm})$ & $2 \cdot 8$ & $2 \cdot 1-3 \cdot 6$ & 3.0 & $2 \cdot 2-3 \cdot 7$ & $3 \cdot 2$ & $2 \cdot 5-3 \cdot 8$ & 0.23 \\
\hline
\end{tabular}

* Group A: mothers received oral vitamin $D_{3} 3000 \mu \mathrm{g}$ within $7 \mathrm{~d}$ of delivery, and then $3000 \mu \mathrm{g}$ at $1.5,2.5,3.5$ months, under supervision. At 3.5 and 6 months, mothers were provided oral vitamin $D_{3}$ for the next 3 months and were instructed to take $3000 \mu \mathrm{g}$ monthly. The baby was given placebo syrup.

$\dagger$ Group B: the baby received $10 \mu \mathrm{g}$ vitamin D preparation orally daily. The mother was given placebo sachets.

$\ddagger$ Group C (control): neither the baby nor the mother was given any vitamin D supplementation. Both were given their respective placebo.

25(OH)D $21(\mathrm{sD} 14 \cdot 25) \mathrm{nmol} / \mathrm{l}(8 \cdot 4(\mathrm{sD} 5 \cdot 7) \mathrm{ng} / \mathrm{ml})^{(5)}$ or median serum $\left.25(\mathrm{OH}) \mathrm{D} 18.5 \mathrm{nmol} / 1(7.4 \mathrm{ng} / \mathrm{ml})^{(12)}\right)$ or in infants aged 2-24 weeks from two other studies from Delhi (which is at a similar latitude as Lucknow) with a median serum $25(\mathrm{OH}) \mathrm{D}$ of $25 \cdot 25($ IQR $6 \cdot 25-42 \cdot 75) \mathrm{nmol} / \mathrm{l}(10 \cdot 1(\mathrm{IQR} 2 \cdot 5-17 \cdot 1) \mathrm{ng} / \mathrm{ml})^{(2)}$ and a mean $25(\mathrm{OH}) \mathrm{D}$ of $29(\mathrm{sD} 20 \cdot 75) \mathrm{nmol} / 1(11 \cdot 6(\mathrm{sD} 8 \cdot 3) \mathrm{ng} / \mathrm{ml})^{(13)}$. In a recent study across three international sites, serum $25(\mathrm{OH}) \mathrm{D}$ in infants was associated with their sun index (sun exposure $\times$ body surface area exposed while outdoors $)^{(14)}$. However, without having a concurrent second control group that did not get repeated sun exposure advice, it is not possible to comment on whether this advice made a difference in our study. Although about $30 \%$ of babies in all three groups were already receiving some formula feed, the vitamin D fortification of which could have contributed to their serum 25(OH)D, the trend of rising serum $25(\mathrm{OH}) \mathrm{D}$ in infancy has also been reported in studies in which babies had not received formula ${ }^{(15)}$.

The next important issue is the dose of vitamin D administered to mothers and babies. Basile et al. $^{(16)}$ studied breast-feeding mothers randomised at 1 month postpartum to vitamin D supplementation of $50(n$ 12) or $100(n$ 13) $\mu \mathrm{g} / \mathrm{d}$ given for 3 months. Results showed that the $100 \mu \mathrm{g} / \mathrm{d}$ regimen was more efficient in raising both maternal and infant serum $25(\mathrm{OH}) \mathrm{D}$ levels and breast milk antirachitic activity than the $50 \mu \mathrm{g} / \mathrm{d}$ regimen. It is worthy of note, however, that maternal mean serum 25(OH)D after 3 months for the $100 \mu \mathrm{g} / \mathrm{d}$ regimen was $107.5 \mathrm{nmol} / 1(43.0 \mathrm{ng} / \mathrm{ml})$, higher than the corresponding group 
receiving $3000 \mu \mathrm{g} / \mathrm{month}$ (amounting to $100 \mu \mathrm{g} / \mathrm{d}$ ) in our study with a mean $25(\mathrm{OH}) \mathrm{D}$ of $61.5 \mathrm{nmol} / 1(24.6 \mathrm{ng} / \mathrm{ml})$. The corresponding infant mean serum $25(\mathrm{OH}) \mathrm{D}$ at 3 months was $77 \mathrm{nmol} / \mathrm{l} \quad(30.8 \mathrm{ng} / \mathrm{ml})$, higher than that of our infants $(53.75 \mathrm{nmol} / \mathrm{l}(21.5 \mathrm{ng} / \mathrm{ml}))$. This difference could be because of the higher baseline maternal mean $25(\mathrm{OH}) \mathrm{D}$ of $71.25 \mathrm{nmol} / \mathrm{l}$ $(28.5 \mathrm{ng} / \mathrm{ml})$ in that group in the study by Basile et al. studies by Hollis et $a l^{(6)}$ also confirmed a maternal dose of 6400 units/d to be adequate and safe, providing similar infant $25(\mathrm{OH}) \mathrm{D}$ as those infants given direct $10 \mu \mathrm{g}$ supplementation daily. At the time of writing, single-dose regimens have cost and potential compliance advantages in India.

A few Indian and international studies have evaluated direct infant vitamin D supplementation. Mutlu et $a l .{ }^{(17)}$ documented that Turkish infants receiving $10 \mu \mathrm{g} / \mathrm{d}$ vitamin $\mathrm{D}$ achieved a mean $25(\mathrm{OH}) \mathrm{D}$ of 106.3 (sD 64.5$) \mathrm{nmol} / \mathrm{l}(42.5$ (sD 25.8) ng/ml). No data on baseline maternal or infant $25(\mathrm{OH}) \mathrm{D}$ were available in this study. In our study, infants receiving $10 \mu \mathrm{g} / \mathrm{d}$ achieved a much lower mean 25(OH)D of $56.5(\mathrm{sD} 23.5) \mathrm{nmol} / \mathrm{l}(22.6(\mathrm{sD} 9.4) \mathrm{ng} / \mathrm{ml})$. The difference could again be because of different baseline $25(\mathrm{OH})$ D levels. In a recent study from India in preterm infants, $20 \mu \mathrm{g} / \mathrm{d}$ of vitamin D was shown to be superior to $10 \mu \mathrm{g} / \mathrm{d}$ at 3 months in preventing vitamin D levels $<50 \mathrm{nmol} / \mathrm{l}(20 \mathrm{ng} / \mathrm{ml})(12.5 v .35 \%)$; however, one infant in the $20 \mu \mathrm{g}$ group had serum $25(\mathrm{OH}) \mathrm{D}$ in the range defined as vitamin D excess $(250-375 \mathrm{nmol} / \mathrm{l}$ or $100-150 \mathrm{ng} / \mathrm{ml})^{(18)}$

The infants did not differ in anthropometric measures at any time point, across the three groups. This finding has been inconsistent in various studies of vitamin D supplementation in infancy ${ }^{(8,19)}$. Over 9 months, parameters for dentition including onset of teeth and number of teeth did not differ among the groups. In a previous study, preterm infants randomised to receive a vitamin D dose of 12.5 or $25 \mu \mathrm{g} / \mathrm{d}$ showed that vitamin $\mathrm{D}$ did not affect maturation of the primary dentition in preterm children $^{(20)}$. The role of vitamin D in defence against infections is still controversial. Some studies support such a finding ${ }^{(21)}$, whereas others do not ${ }^{(8,22)}$.

There were no serious adverse events in any group in our study. A similar proportion of infants developed transient hypercalcaemia in all three groups. This phenomenon has been recently documented in newborns by other investigators reporting on supplementation of vitamin D in pregnancy. The hypercalcaemia was asymptomatic, and it spontaneously resolved; there is no clear explanation for it ${ }^{(23)}$. Notwithstanding this, the fact that one infant's and two mothers' serum 25(OH)D were documented to be slightly $>125 \mathrm{nmol} / \mathrm{l}$ warrants that larger studies should further document safety of the maternal supplementation dose used in our study.

The strengths of our study include the randomised, placebocontrolled design and the direct supervision of vitamin D administration to mothers. The fact that the baby is unclothed during the massage allowed us to make a serious attempt at harnessing the abundant sunshine. The results of parameters such as PTH, P and alkaline phosphatase highlight the biological relevance of the vitamin supplementation. An important limitation of our study is the $34 \%$ dropout at primary outcome, with a potential for bias in the results. Although a significant proportion of infants received formula feeds in addition to breast milk, this was similar in the three groups and may not have influenced the outcome. We were unable to quantify the exact quantities of formula being consumed by each infant, but babies not receiving any formula at 3.5 months had almost identical $25(\mathrm{OH}) \mathrm{D}$ as those receiving it. Third, the duration of infections did not remain significantly different when respiratory and diarrhoeal infections were separately analysed; a larger study is needed before a firm conclusion can be drawn regarding this outcome. Last, no X rays were performed on the infants who had elevated alkaline phosphatase, to look for rickets.

In summary, our findings suggest that an oral dose of $3000 \mu \mathrm{g} /$ month cholecalciferol given to lactating women is equivalent to daily dosing of the infant with $10 \mu \mathrm{g}$ in raising infant serum 25(OH)D at 3.5 and improving relevant biological indices. Both dose regimens, given along with sun exposure, are superior to traditional durations of sun exposure alone in maintaining normal infant $25(\mathrm{OH}) \mathrm{D}$ at 3.5 months, and providing protection from elevated alkaline phosphatase and possibly from infectious morbidity. These doses of vitamin D correspond to the IOM-recommended maximum daily upper limit of intake of $100 \mu \mathrm{g}$ for lactating women, but the single monthly dosing lends itself to administration under observation and benefits both mother and child. These findings, including the safety of the maternal dose, need confirmation in other settings and populations.

\section{Acknowledgements}

The authors thank Anshu Srivastava, Arjun Singh, Pallavi Tiwari and Abhishek Kumar for their help in conduct of the study.

This work was supported by grants to V. B. from the Department of Biotechnology, Government of India (BT/PR13985/SPD/11/297/2010) and the Indian Society for Bone and Mineral Research. The funding agencies had no role in the study design; the collection, analysis and interpretation of data; the writing of the report; and the decision to submit the paper for publication.

D. D. C. planned and conducted the study, analysed the data and wrote the first draft of the manuscript; J. K. enrolled study subjects, conducted the study, analysed data and wrote the first draft of the manuscript; S. N. S. conceptualised the study, supervised all details, analysed the data and edited the manuscript; A. A. and U. S. supervised subject enrolment and acquisition of data and approved the manuscript; V. D. planned the conduct of the study and edited the manuscript; V. R. supervised conduct of the study and approved the manuscript; V. B. conceptualised the study, planned and supervised its conduct, analysed the data and edited the manuscript and will take guarantee for the manuscript.

The authors declare that there are no conflicts of interest.

\section{Supplementary material}

For supplementary material/s referred to in this article, please visit http://dx.doi.org/doi:10.1017/S0007114516001756 


\section{References}

1. Mehrotra P, Marwaha RK, Aneja S, et al. (2010) Hypovitaminosis $\mathrm{D}$ and hypocalcemic seizures in infancy. Indian Pediatr 47, 581-586.

2. Jain V, Gupta N, Kalaivani M, et al. (2011) Vitamin D deficiency in healthy breastfed term infants at 3 months \& their mothers in India: seasonal variation \& determinants. Indian J Med Res 133, 267-273.

3. Wagner CL \& Greer FR (2008) Prevention of rickets and vitamin $\mathrm{D}$ deficiency in infants, children, and adolescents. Pediatrics 122, 1142-1152.

4. Misra M, Pacaud D, Petryk A, et al. (2008) Vitamin D deficiency in children and its management: review of current knowledge and recommendations. Pediatrics 122, 398-417.

5. Sachan A, Gupta R, Das V, et al. (2005) High prevalence of vitamin D deficiency among pregnant women and their newborns in northern India. Am J Clin Nutr 81, 1060-1064.

6. Hollis BW, Wagner CL, Howard CR, et al. (2015) Maternal versus infant vitamin $\mathrm{D}$ supplementation during lactation: a randomised controlled trial. Pediatrics 136, 625-634.

7. Ala-Houhala M, Koskinen T, Terho A, et al. (1986) Maternal compared with infant vitamin D supplementation. Arch Dis Child 61, 1159-1163.

8. Kumar GT, Sachdev HS, Chellani H, et al. (2011) Effect of weekly vitamin D supplements on mortality, morbidity, and growth of low birthweight term infants in India up to age 6 months: randomised controlled trial. BMJ 342, 2975.

9. Ross AC, Manson JE, Abrams SA, et al. (2011) The 2011 report on dietary reference intakes for calcium and vitamin D from the Institute of Medicine: what clinicians need to know. J Clin Endocrinol Metab 96, 53-58.

10. Kuppuswamy B (1981) Manual of Socioeconomic Status (Urban). Delhi: Manasayan.

11. Indian Labour Journal (2012) Vol. 53 [Labour Bureau, editor]. Shimla: Government of India. www.labourbureaunew.gov.in (accessed November 2015).

12. Kalra P, Das V, Agarwal A, et al. (2012) Effect of vitamin D supplementation during pregnancy on neonatal mineral homeostasis and anthropometry of the newborn and infant. Br J Nutr 108, 1052-1058.

13. Seth A, Marwaha RK, Singla B, et al. (2009) Vitamin D nutritional status of exclusively breast fed infants and their mothers. J Pediatr Endocrinol Metab 22, 241-246.

14. Dawodu A, Davidson B, Woo JG, et al. (2015) Sun exposure and vitamin D supplementation in relation to vitamin D status of breastfeeding mothers and infants in the global exploration of human milk study. Nutrients 7, 1081-1093.

15. Challa A, Ntourntoufi A, Cholevas V, et al. (2005) Breastfeeding and vitamin D status in Greece during the first 6 months of life. Eur J Pediatr 164, 724-729.

16. Basile LA, Taylor SN, Wagner CL, et al. (2006) The effect of high-dose vitamin $\mathrm{D}$ supplementation on serum vitamin D levels and milk calcium concentration in lactating women and their infants. Breastfeed Med 1, 27-35.

17. Mutlu GY, Kusdal Y, Ozsu E, et al. (2011) Prevention of vitamin D deficiency in infancy: daily $400 \mathrm{IU}$ vitamin D is sufficient. Int J Pediatr Endocrinol 2011, 4.

18. Natarajan CK, Sankar MJ, Agarwal R, et al. (2014) Trial of daily vitamin D supplementation in preterm infants. Pediatrics $\mathbf{1 3 3}$, e628-e634.

19. Vieth Streym S, Kristine Moller U, Rejnmark L, et al. (2013) Maternal and infant vitamin D status during the first 9 months of infant life-a cohort study. Eur J Clin Nutr 67, 1022-1028.

20. Backstrom MC, Aine L, Maki R, et al. (2000) Maturation of primary and permanent teeth in preterm infants. Arch Dis Child Fetal Neonatal Ed 83, F104-F108.

21. Aluisio AR, Maroof Z, Chandramohan D, et al. (2013) Vitamin $\mathrm{D}_{3}$ supplementation and childhood diarrhea: a randomized controlled trial. Pediatrics 132, e832-e840.

22. Bergman P, Lindh AU, Bjorkhem-Bergman L, et al. (2013) Vitamin D and respiratory tract infections: a systematic review and meta-analysis of randomized controlled trials. PLOS ONE 8, e65835.

23. Harrington J, Perumal N, Al Mahmud A, et al. (2014) Vitamin D and fetal-neonatal calcium homeostasis: findings from a randomized controlled trial of high-dose antenatal vitamin D supplementation. Pediatr Res 76, 302-309. 